\title{
Commentary on The Case of Ms. Q: A Demonstration of Integrative Psychotherapy Guided by "Core Clinical Hypotheses"
}

\section{Issues in the Development, Practice, Training, and Research of Integrative Therapies GEORGIOS K. LAMPROPOULOS ${ }^{\mathrm{a}, \mathrm{b}}$}

${ }^{a}$ Educational Psychology and Learning Systems, Florida State University, Tallahassee, FL

b

Correspondence should be sent to Georgios K. Lampropoulos, Department of Educational Psychology and Learning, Systems, 3210 Stone Building, Florida State University, Tallahassee, FL 32306-4453.

E-mail: gklampropoul@yahoo.com

\begin{abstract}
This commentary on the integrative case study of Ms. Q by Barbara Ingram (2009) aims to discuss relevant theoretical, clinical, research, and training issues in the development and practice of integrative/eclectic psychotherapy models. It begins with a description of the contributions and position of Ingram's model within the current psychotherapy integration literature. It then examines issues in the development and practice of psychotherapy integration approaches, and concludes by highlighting the urgent need for research on the effectiveness and training in integrative practices in naturalistic clinical settings.
\end{abstract}

Keywords: psychotherapy integration; eclecticism; theory, research, and training

\section{POSITION AND CONTRIBUTIONS OF INGRAM'S MODEL TO PSYCHOTHERAPY INTEGRATION}

The psychotherapy integration movement has been around for a few decades now, with its official organization, the Society for the Exploration of Psychotherapy Integration (SEPI; http://www.cyberpsych.org/sepi), celebrating 25 years of existence this year. There have been several integrative/eclectic models discussed in the literature, which typically fall within one of the four major routes to psychotherapy integration — via eclecticism, via common factors across models, via theoretical integration across models, or via assimilative integration of strategies from one model into another) - or a combination of them (Norcross \& Goldfried, 2005). Although there is no one best or prominent way of practicing psychotherapy integration, between one- to two-thirds of surveyed clinicians report that they are integrative or eclectic in their theoretical orientation (Norcross, 2005). Further, consistent with clinical observation, there is some research evidence to suggest that the vast majority of clinicians are at least partially integrative/eclectic in their practice (Norcross, 2005; Tierney, 2003).

The integrative approach discussed by Ingram (2006; 2009) is in line with other integrative efforts to systematically consider and integrate concepts and strategies from all major theoretical approaches in one's way of practicing. Specifically, it is consistent with the 
Transtheoretical Model (Prochaska \& DiClemente, 2005) and the Hill Three-Stage Model of Helping (Hill, 2004) that describe the integrative use of various clinical skills/strategies from all major theories of therapy (although these models do that along a specific continuum of stages of change in therapy). Ingram's approach is even closer to integrative/eclectic approaches such as Lazarus’s (2005) Multimodal Therapy and Brooks-Harris’s (2008) Multitheoretical Psychotherapy, as well as my own writings (e.g., Lampropoulos, Spengler, Dixon, \& Nicholas, 2002), in that it aspires to achieve a comprehensive client assessment in terms of all the major theoretical models and concepts, and to tailor these concepts and interventions to the specific client. In that sense, it can probably be most accurately categorized as a comprehensive eclectic model, operating within a broad and clearly defined multitheoretical framework.

A major contribution of Ingram's approach is the development of her 28 core clinical hypotheses from seven major theoretical domains. These are designed to help clinicians assess clients multitheoretically and to develop integrative case conceptualizations. Another unique emphasis is that this approach focuses on the integration of clinical hypotheses (as opposed to interventions), targeting primarily an integrative conceptualization. However, the clinical interventions that correspond to these hypotheses seem to be typically (but not necessarily) theoretically consistent, resulting in integrative treatments.

The 28 core clinical hypotheses seem to summarize the central unique elements of the major different theoretical domains that are relevant to clinical practice. In her book, Ingram (2006) goes into great and effective detail in describing the 28 hypotheses and related theoretical material, as well as the possible relations and integrations of these 28 hypotheses with each other. In doing this, she has done an important job in presenting the gist of major theories and concepts that an integrative/eclectic student or clinician ought to know to practice integratively at a basic level. After reading Ingram's (2009) case of Ms. Q, one can also appreciate the level of sophistication in assessing, conceptualizing, and treating a client integratively via the use of the 28 core hypotheses. These 28 core hypotheses arguably provide a comprehensive clinical and theoretical toolbox to choose and integrate hypotheses and strategies throughout treatment, as needed. In my view, it is exactly this richness in the integrative conceptualization that allowed Ingram as the therapist in the case of Ms. Q to find appropriate conceptualizations and to tailor them to the needs and dynamics of the client at many different levels, increasing the chance that the client would find them meaningful and beneficial in therapy. Indeed, research suggests that individualized case formulations are beneficial to treatment, particularly for complex cases (see brief review in Kendjelic \& Eells, 2007). Although this is an empirical question, it is likely that integrative individualized case formulations, because of their inherent flexibility and comprehensiveness, could be even more effective compared to single-theory formulations.

In sum, Ingram has successfully provided a relatively succinct and comprehensive way to introduce students and therapists to the eclectic/integrative practice of therapy, via the use of the 28 core clinical hypotheses. However, despite its obvious utility in the practice and training of integrative/eclectic therapists, Ingram's approach is not immune to some of the inherent difficulties of developing and applying integrative treatments. Some such issues are introduced below. 


\section{ISSUES IN THE DEVELOPMENT AND PRACTICE OF INTEGRATIVE/ECLECTIC APPROACHES}

There is a major issue in the development of an integrative/eclectic approach like Ingram's that concerns the process of identifying the most important and unique elements of different psychotherapy theories. Specifically, how one can ensure (a) that all the central concepts and strategies of each theory are included; (b) that these concepts are adequately and succinctly described and defined at the most appropriate level, without leaving out theoreticallyimportant material; and (c) that these concepts are mutually exclusive and non-overlapping with each other, both within different theories and across theories (which can be challenging, given the existence of common factors; Lampropoulos, 2000). From a research standpoint, this will likely be best accomplished by starting with an exhaustive review of the psychotherapy theory literature (including integrative literature), and by using a team of judges (expert clinicians and researchers in different theories of therapy, including psychotherapy integration) to develop and refine a list that will meet the aforementioned three criteria. Even then, this promises to be an arduous task, particularly as it concerns criteria (b) and (c). In such an effort to identify the unique elements of each psychotherapy theory, Ingram's list of 28 hypotheses may represent an excellent starting point. Of course, one may also argue that the existing list of 28 hypotheses is an adequate tool for practical training and clinical purposes and could be used effectively without perfectly meeting the aforementioned three criteria.

There is also a major issue in how to apply an integrative/eclectic approach like Ingram's 28 hypotheses. Specifically, how can one make sure (a) that it is relatively easy to distinguish between hypotheses; (b) that there is some guidance regarding when and how to choose and prioritize the core clinical hypotheses; and (c) that there is some guidance regarding how to integrate the core clinical hypotheses such that the various hypotheses are compatible with each other, resulting in a coherent and acceptable formulation to the client. Criterion (a) involves the desired level of mutual exclusivity between the unique ingredients of Ingram's 28 core hypotheses from different therapies as discussed earlier. For example, some students or practitioners could find it confusing to choose between potentially overlapping core hypotheses, such as those involving a Faulty Cognitive Map, Dysfunctional Self-Talk, and the Reenactment of Early Childhood Experiences. In response to criterion (b), Ingram (2006) has provided guidance regarding for which clinical problems each core hypothesis should be considered a good match. However, given the shear number of the core hypotheses and their complexity, some additional guidelines would be helpful in prioritizing and identifying the possible importance of each of the core hypotheses. Identifying a few general principles could provide some guidance here, such as starting by focusing on a client's past, deep-seated clinical issues and then moving to the current problem manifestations (or the reverse); or starting by focusing on how to prioritize the systems vs. the individual core hypotheses, or the biological vs. the psychological ones. Lastly, as it concerns criterion (c), Ingram (2006) has provided suggestions regarding which core hypotheses might be compatible with each other. However, from an assimilative integration point of view (Lampropoulos, 2001; Messer, 1992), integrating a variety of different concepts and strategies in treatment will result in a unique product that should be re-examined for its conceptual coherence and acceptability, at least as it concerns the client's perception. In the end, one might question how much impact the issues described in the aforementioned three criteria 
would have at the clinical and training level. These are questions that will be best examined via clinical research and observation. My sense is that they may have some meaningful effect on future practice; however, most students and clinicians will still be able to practice integratively and effectively at some level using Ingram's present system.

\section{TRAINING AND RESEARCH ISSUES IN PSYCHOTHERAPY INTEGRATION}

This integrative case study raises the opportunity to discuss important relevant research and training issues in psychotherapy integration. First, it is impressive seeing an experienced therapist and academician like Ingram, who has received training in various theories and has developed an integrative approach, demonstrating its seamless and effective use in the case of Ms. Q. But how easy would it be to train students and professional therapists in an integrative approach like Ingram's? Although there is some evidence that not only professionals but also training programs tend to favor integrative/eclectic practices (Lampropoulos \& Dixon, 2007; Norcross, 2005), the feasibility and effectiveness of training students or more experienced practitioners in integrative conceptualizations and treatments needs to be examined empirically. At a minimum, trainees would have to master two or more different theoretical orientations in order to practice integratively, and one might expect that learning a complex multitheoretical integrative model at the conceptual and clinical level would require significant time and supervision. Further, there seems to be a split in opinion among training directors regarding which is the best way to teach psychotherapy integration. A general majority (47-57\% of directors) favor training students to be minimally competent in various models first. Fewer support the options of first training students to be proficient in one therapeutic model before they receive integrative training (21-38\% of directors), or training students in a specific integrative/eclectic model from the outset (15-21\% of directors; Lampropoulos \& Dixon, 2007). In any case, to date, to the best of my knowledge there has been virtually no research on integrative training issues, and thus this is an area in which much more attention is needed.

In addition to training issues, an even more fundamental issue concerns the efficacy and effectiveness of integrative case conceptualizations and therapies themselves. At this point, we lack sufficient empirical data regarding how integrative therapies are practiced and what are their outcomes, particularly in naturalistic practice environments (although some research on specific integrative/eclectic models exists; see Schottenbauer, Glass, \& Arnkoff, 2005). At a minimum, I propose (a) that integrative practitioners utilize brief process and outcome measures in their routine clinical practice to monitor and evaluate common factors such as the therapeutic alliance; and (b) that they use the resulting data to evaluate both the employment of integrative strategies and the achievement of process and outcome goals, including the measurement of clinically significant change (see also Lampropoulos, 2000, for some suggestions on measures). This could increase the value of information collected via case studies, and/or it could be used in largersample research designs based on the clientele of one or more integrative clinicians (see Lampropoulos, Goldfried, et al., 2002, for recommendations on practitioner research).

In conclusion, research on the training and outcomes of integrative therapies in routine practice is sorely lacking. Given that a very large percentage of therapists identify and practice 
integratively/eclectically, there is an urgent need to know more about their strategies of integrative/eclectic practice and their outcomes, along with appropriate methods to improve training in this type of therapy. The development of systematic models of integrative/eclectic practice could aid training efforts in psychotherapy integration, but these models should also be empirically researched in terms of their clinical effectiveness and training feasibility. Conducting pragmatic case studies such as Ingram's (2009) case of Ms. Q is one approach to such empirical research. While Ingram is to be commended for the richness and rigor of the qualitative data she presents, as a contribution to empirical research her case study would have been enhanced by also including results on standardized quantitative measures, to provide a normative context for the individual case, as is illustrated in other case studies published in this PCSP journal (e.g., see Clement, 2007; and Mohlman et al., 2008).

\section{REFERENCES}

Brooks-Harris, J. E. (2008). Integrative multitheoretical psychotherapy. Boston: Houghton Mifflin.

Clement, P.W. (2007). Story of “Hope:” Successful treatment of obsessive-compulsive disorder.” Pragmatic Case Studies in Psychotherapy [Online], Vol. 3(4), Article 1, 1-36. Available: http://hdl.rutgers.edu/1782.1/pcsp_journal

Hill, C. E. (2004). Helping skills: Facilitating exploration, insight, and action (2nd ed.). Washington, DC: American Psychological Association.

Ingram, B. L. (2006). Clinical case formulations : Matching the integrative treatment plan to the client. Hoboken, N.J.: Wiley.

Ingram, B.L. (2009). The case of Ms. Q: A demonstration of integrative psychotherapy guided by “Core Clinical Hypotheses.” Pragmatic Case Studies in Psychotherapy [Online], Vol. 5(1), Article 1, 1-42. Available: http://hdl.rutgers.edu/1782.1/pcsp_journal

Kendjelic, E. M., \& Eells, T. D. (2007). Generic psychotherapy case formulation training improves formulation quality. Psychotherapy, 44, 66-77.

Lampropoulos, G. K. (2000). Definitional and research issues in the common factors approach to psychotherapy integration: Misconceptions, clarifications, and proposals. Journal of Psychotherapy Integration, 10, 415-438.

Lampropoulos, G. K. (2001). Bridging technical eclecticism and theoretical integration: Assimilative integration. Journal of Psychotherapy Integration, 11, 5-19.

Lampropoulos, G. K., \& Dixon, D. N. (2007). Psychotherapy integration in internships and counseling psychology doctoral programs. Journal of Psychotherapy Integration, 17, 185208.

Lampropoulos, G. K., Goldfried, M., Castonguay, L. G., Lambert, M., Stiles, W. B., \& Nestoros, J. N. (2002). What kind of research can we realistically expect from the practitioner? Journal of Clinical Psychology, 58, 1241-1264.

Lampropoulos, G. K., Spengler, P. M., Dixon, D. N., \& Nicholas, D. R. (2002). How psychotherapy integration can complement the scientist-practitioner model. Journal of Clinical Psychology, 58, 1227-1240.

Lazarus, A. A. (2005). Multimodal therapy. In J. C. Norcross \& M. R. Goldfried (Eds.), Handbook of psychotherapy integration (2nd ed., pp. 105-120). New York: Oxford. 
Messer, S. B. (1992). A critical examination of belief structures in integrative and eclectic psychotherapy. In J. C. Norcross \& M. R. Goldfried (Eds.), Handbook of psychotherapy integration (pp. 130-165). New York: Basic Books.

Mohlman, J., Cedeno, L.A., Price, R.B., Hekler, E.B., Yan, G.W., \& Fishman, D.B. (2008). Deconstructing Demons: The Case of Geoffrey. Pragmatic Case Studies in Psychotherapy[Online], Vol 4(3), Article 1, pp. 1-39. Available: http://hdl.rutgers.edu/1782.1/pcsp_journal

Norcross, J. C. (2005). A primer on psychotherapy integration. In J. C. Norcross \& M. R. Goldfried (Eds.), Handbook of psychotherapy integration (2nd ed., pp. 3-23). New York: Oxford.

Norcross, J. C., \& Goldfried, M. R. (Eds.). (2005). Handbook of psychotherapy integration (2nd ed.). New York: Oxford.

Prochaska, J.O., \& DiClemente, C.C. (2005). The transtheoretical approach. In J. C. Norcross \& M. R. Goldfried (Eds.), Handbook of psychotherapy integration (2nd ed., pp. 147-171). New York: Oxford.

Schottenbauer, M. A., Glass, C. R., \& Arnkoff, D. B. (2005). Outcome research on psychotherapy integration. In J. C. Norcross \& M. R. Goldfried (Eds.), Handbook of psychotherapy integration ( $2^{\text {nd }}$ ed., pp. 459-493). New York: Oxford.

Tierney, G. T. (2003). Psychotherapy integration: Examination of clinical utilization. (Doctoral Dissertation, University of North Dakota, 2003). Dissertation Abstracts International, 63 (8-B), 3943. 